\title{
Yüksek Şiddetli Egzersiz Sonrasında Pasif, Kor Egzersizleri ile Kombine Pasif ve Aktif Toparlanmanın Kandan Laktik Asit Eliminasyonu Üzerine Etkisi Effect of Passive, Passive Combined with Core Exercises and Active Recovery on Blood Lactate Clerance Following High Intensity Exercise
}

\author{
Araştırma Makalesi
}

'Tahir Hazır, ${ }^{2}$ Şükrü Gül

1 Hacettepe Üniversitesi, Spor Bilimleri Fakültesi, Egzersiz ve Spor Bilimleri Bölümü, Beytepe - Ankara, 2 IF Gnistan Spor Kulübü, Helsinki, Finlandiya

\section{öz}

u çalışmanın amacı yüksek şiddetli egzersizler sonrasında pasif, kor egzersizleri ile kombine pasif ve aktif toparlanmanın laktik asit eliminasyonu üzerine etkisini incelemektir. Onbir aktif spor yapan erkek spor bilimleri öğrencisine (yaş $=25.7$ $\$ 3.3$ yıl, boy $=182.6 \pm 7.2 \mathrm{~cm}$, vücut yağ yüzdesi $=\% 12.25 \pm 3.2$ ) üç kez yüksek şiddette (Wingate Test) egzersiz sonrasında 20'şer dk sürelerle pasif, rezerv kalp atım hızının \% 40'ında aktif ve kor egzersizleri ile kombine pasif (10 dk stabil kor egzersi$z i+10 \mathrm{dk}$ pasif) toparlanma yaptırılmıştır. Dinlenik durumda ve test sonu ve toparlanmanın 2., 5., 10., 15., 20. dk'larında kandan laktik asit (LA) ölçülmüştür. Toparlanma esnasında ölçülen değişkenler arasındaki farklar Tekrarlı Ölçümlerde Varyans Analizi ile test edilmiştir. Test öncesinde ölçülen vücut ağırlığı, dinlenik KAH ve LA değerleri benzerdir ( $p>0.05$ ). Wingate testleri sonunda ölçülen KAHzirve ve LA değerleri de benzer bulunmuştur ( $p>0.05$ ).

\section{A BSTRACT}

The purpose of the present study was to assess the effect of passive recovery, passive recovery combined with core exercises, and active recovery on blood lactate clearance following high intensity exercise. Eleven male active sport sciences students (mean \pm SD; age, $25.7 \pm 3.3$ year; height, $186.2 \pm 7.2$ $\mathrm{cm}$; body fat percent, $12.25 \pm 3.2$ ), performed the following 20-min recovery treatments in a random order after a Wingate test (WanT): 1) passive, 2) passive combined with core exercises, 3 ) active (at $40 \%$ HRR). Blood lactate (BL) was measured at rest, after the WanT, and at 2nd, 5th, 10th, 15th, 20th minutes of recovery. The differences between the variables measured at rest and during recovery were tested by repeated measures analysis of variance. Pre-exercise body weight, resting $\mathrm{HR}$ and $\mathrm{BL}$ were similar in all trials ( $p>0.05$ ). HRpeak and BL values were also similar after the WanT. There were no significant differences in LA concentration at $2 \mathrm{nd}$, 5th, 10th, 15th, and 20th 
Farklı toparlanma protokollerinin 2., 5., 10., 15. ve 20. dk'larında ölçülen kan LA konsantrasyonları arasında anlamlı fark saptanmamıştır ( $p>0.05$ ). Bu çalışmanın bulguları, yüksek şiddette egzersiz sonrasında pasif, kor egzersizleri ile kombine pasif ve aktif toparlanmanın kandan LA'nın uzaklaştırılma hızı üzerine etkisi olmadığını göstermiştir.

\section{Anahtar Kelimeler}

Pasif toparlanma, Aktif toparlanma, Stabil kor egzersizi, Laktik asit

\section{Giriş}

Yüksek şiddetli egzersizlerde kas metabolizmasında baskın enerji sistemi anaerobik glikoliz olduğu için bu tip egzersizler esnasında kas ve kanda laktik asit (LA) konsantrasyonu önemli ölçüde artar (Bangsbo ve diğ., 1993; Sahlin ve diğ., 1987). LA çok kuvvetli asit olduğu için Laktat ${ }^{-}+\mathrm{H}^{+}$iyonu şeklinde ayrışırak metabolik asidoza ( $\mathrm{pH}$ 'da azalma) ve yorgunluğa neden olur (Robergs ve diğ., 2004; Allen ve diğ., 2008). Bu nedenle kas ve kandan LA'nın uzaklaştırılma hızı, özellikle tekrarlı egzersiz performansını geliştirdiği (Greenwood ve diğ. 2008; Thiriet ve diğ., 1993) için toparlanmanın önemli bir bölümünü oluşturur.

Egzersiz sonrasında LA'nın optimal hızda eliminasyonu ve sonraki egzersiz performansına etkisi ile ilgili olarak uygulanan toparlanma stratejileri ve fizyolojik cevaplar, toparlanma süresine ve egzersizin tipine bağlı olarak değişkenlik gösterir. Kısa süreli (15 - 30 sn) toparlanmayı içeren kısa süreli tekrarlı egzersizlerde pasif toparlanmanın (PT) aktif toparlanmadan (AT) daha değerli olduğu gösterilmiştir (Scanlan ve Madueno, 2016; Spencer ve diğ., 2008; Spencer ve diğ., 2006; Dupont ve diğ., 2004). Örneğin $V_{2 m a k s}$ hızının \% 120'sine karşılık gelen hızda 15 sn aktif (maksimal aerobik hızın \% 50'sinde) ve 15 sn pasif toparlanma içeren 15 sn tekrarlı koşu sırasında yorgunluğa ulaşma zamanı pasif toparlanmalı tekrarlı koşuda 745 sn, aktif toparlanmalıda 445 sn olarak ölçülmüştür (Dupont ve diğ., 2003). Benzer şekilde $10 \times 20$ m pasif toparlanm ile uygulanan tekrarlı sprint minutes of different recovery protocols. The results of this study suggest that passive, passive combined with core exercises, and active recovery had similar effect on the removal of LA from the blood following high intensity exercise.

\section{Key Words}

Passive recovery, Active Recovery, Stabile core exercise, Lactic acid

performansı aktif toparlanma ile uygulanan tekrarlı sprint performansından daha yüksek bulunmuştur (Scanlan ve Madueno, 2016). Bu tip tekrarlı egzersizlerde kısa süreli aktif toparlanma sırasında hemoglobin ve myoglobinin daha az oksijen bağlaması nedeniyle daha az kreatin fosfat sentezlendiği ve daha az laktatın uzaklaştırıldığı kabul edilmektedir (Spencer ve diğ., 2008; Spencer ve diğ., 2006; Dupont ve diğ., 2003). Uzun süreli toparlanmayı içeren (5 - 60 dk) tek ya da tekrarlı egzersizlerde PT ile karşılaştırıldığında AT esnasında LA'nın kandan uzaklaştırılma hızı (Riganas ve diğ., 2015; Devlin ve diğ., 2014; Menzies ve diğ., 2010; Baldari ve diğ., 2005; Baldari ve diğ., 2004; Thiret ve diğ., 1993) ve tüm çalışmalarda gösterilmemiş olmakla beraber (Lopes ve diğ., 2014; Ouergui ve diğ., 2014; McAinch ve diğ., 2004) sonraki egzersiz performansı (Greenwood ve diğ., 2008; Thiriet ve diğ., 1993) daha yüksektir. Kan LA konsantrasyonunun bir bölümü toparlanmanın erken döneminde glikoneogenezis yoluyla glikoz üzerinden glikojene çevrilirken (Medbo ve diğ., 2006; Palmer ve diğ., 1997) büyük bölümü başlıca iskelet kaslarında ve diğer organlarda aerobik enerji sisteminde yakıt olarak oksitlenerek elimine edilir (Adeva-Andany ve diğ., 2014; van Hall, 2010; Brooks, 1991). AT düşük şiddette aerobik egzersizler şeklinde uygulandığı için bu toparlanma tipinde kasın metabolik hızı (van Hall, 2000) ve sistemik kan akımı (Bangsbo ve diğ., 1993) diğer toparlanma tiplerinden daha yüksektir. Bu nedenle AT'de LA'nın oksidasyon yoluyla kandan uzaklaştırılma hızı artar. 
Aktif ve pasif toparlanma ile karşılaştırıldığında masaj (Robertson ve diğ., 2004; Gupta ve diğ., 1996), dinamik germe (Miladi ve diğ., 2011), elektromyostimulasyon (Heyman ve diğ., 2009) ve soğuk su (Masi ve diğ. 2007; Heyman ve diğ., 2009) gibi toparlanma uygulamaları ile ilgili bulgular çelişkilidir. Robertson ve diğ. (2004), PT ile karşılaştırıldığında masajın yüksek şiddette tekrarlı bisiklet egzersiz performansında ve sonrasında laktat kinetiğinde ölçülebilir bir fizyolojik etkiye neden olmadığını göstermişlerdir. Buna karşılık yüzücülerde yapılan bir çalışmada egzersiz sonrası kandan LA'nın uzaklaştırılma hızının AT > masaj > PT ve sonraki egzersiz performansının (AT = Masaj) $>$ PT şeklinde gözlenmiștir (Rasooli ve diğ., 2012). Martin ve diğ. (1998) ve Gupta ve diğ. (1996), masaj ve PT esnasında LA'nın kandan uzaklaştırılma hızının benzer ve AT'den yavaş olduğunu saptamışlardır. Amatör boksörlerde yapılan bir çalışmanın sonuçları da atletik performans ve fizyolojik cevaplarda masaj ve PT arasında anlamlı bir fark olmadığını göstermiş olmakla beraber (Hemmings ve diğ., 2000), tekrarlı egzersiz performansının ve kandan LA'nın uzaklaştırılma hızının, masajla kombine AT'de PT, sadece AT ve masaj uygulamalarından daha yüksek olduğu gözlenmiştir (Monedero ve Donne, 2000). Paoli ve dig. (2013) yaptıkları bir çalışmada da ozonlanmış masaj yağı ile yapılan masaj sonrasında LA'nın kandan uzaklaştırılma hızı ve tekrarlı egzersiz performansının ozonsuz masaj ve AT'den yüksek, yorgunluk algısının daha düşük olduğunu saptamışlardır. Masaja benzer şekilde dinamik germe egzersizleri içeren toparlanmada hem LA'nın uzaklaştırılma hızının hem de tekrarlı egzersiz performansının ve yorgunluk zamanının AT ve PT'den daha iyi olduğu gösterilmiştir (Miladi ve diğ., 2011). Çalışmalardan elde edilen sonuçlar arasındaki çelişkiler AT'de kullanılan egzersiz şiddeti (Toubekis ve diğ., 2011; Menzies ve diğ., 2010; Baldari ve diğ., 2004), bireyin antrenman durumu (Gmada ve diğ., 2005; Fukuba ve diğ., 1999; Taoutaou ve diğ., 1996), ve topar- lanma süresi (Toubekis ve diğ., 2011; Toubekis ve diğ., 2008) gibi yöntemsel farklılıklardan kaynaklanıyor olabilir.

Gövde kasları, daha spesifik olarak vücudun lumbo-pelvik bölgesindeki kaslar (Willardson, 2007), hareket esnasında vücudun alt ve üst bölümleri arasında bağlantı kurulmasında ve enerjinin transfer edilmesinde, gövdeye yansıyan yükü desteklemede, omurganın ve sinir köklerinin korunmasında önemli rol oynar (Shirey ve diğ., 2012). Kor stabilite egzersizleri genel olarak nedensiz bel ağrılarının rehabilitasyonunda kullanılmakla beraber (Zhang ve diğ., 2015; Hides ve diğ., 2001), bu egzersizlerin sağlıklı bireylerde ve sporcularda denge (Kahle ve Gribble, 2009) ve atletik performansı (Imai ve diğ., 2014; Butcher ve diğ., 2007) da önemli ölçüde geliştirdiği belirlenmiştir. Kor stabilite egzersizleri sonrasında sağlıklı bireylerde 5000 m koşu (Sato ve Mokha, 2009), sporcularda dikey sıçrama (Sharma ve diğ., 2012; Butcher ve diğ., 2007) performansında anlamlı artış saptanmıştır. Genç erkek futbolcularda yapılan bir çalışmada haftada üç gün 12 haftalık kor stabilite egzersizleri sonrasında statik denge, aerobik dayanıklılık, 30 m sürat, reaktif kuvvet indeksi ve dikey sıçrama performansında anlamlı artış bulunmuştur (Imai ve diğ., 2014). Benzer şekilde genç elit futbolcularda yapılan bir diğer çalışmada da 9 haftalık kor kuvvet antrenmanlarının gövde ekstansör kaslarında \% 5 anlamlı artışla beraber 10-20 m sprint ve şut performansını önemli ölçüde geliştirdiği gösterilmiştir (Prieske ve diğ., 2016). Kor kuvvet egzersizleri bel ağrısından korunma, rehabilitasyon, denge ve atletik performansın geliştirilmesinde kullanılmakla beraber, bu egzersizlerin kandan laktik asitin uzaklaştırılması üzerine etkisinin olup olmadığı da araştırılmıştır. Navalta ve Hrncir Jr. (2007), yüksek şiddette anaerobik egzersizden hemen sonra uygulanan kor egzersiz esnasında kandan LA'nın uzaklaştırılma hızının pasif toparlanmadan daha yüksek olduğunu kayıt etmişlerdir. Ancak söz konusu çalışmada anaerobik egzersiz sonrasında kor stabilite egzersizlerinin LA'nın 
kandan uzaklaştırılma hızı üzerine etkisi egzersizden $5 \mathrm{dk}$ sonra tek bir nokta ölçüm üzerinden değerlendirilmiş, kan LA konsantrasyonunun zamana karşı değişimi incelenmemiştir. Egzersiz sonrası PT ve aktif toparlanma sırasında kandan LA'nın uzaklaştırılma hızını gösteren zamana karşı değişim grafikleri arasında önemli farklar vardır (Gupta ve diğ., 1996). Ek olarak farklı şiddette uygulanan aktif toparlanmalar sırasında kandan LA'nın uzaklaştırılma hızını yansıtan grafiklerin de kendi içinde farklı olduğu gözlenmiştir (Baldari ve diğ., 2004). Kan LA konsantrasyonunun PT sırasında 30. dk'ya, bireysel solunumsal eşiğin üstündeki şiddette 15. dk'ya, bireysel solunumsal eşik ve altındaki şiddetlerde 20. dk'ya kadar anlamlı derecede azaldığı saptanmıştır (Baldari ve diğ., 2004). Bu bulgulardan da anlaşılacağı gibi toparlanma sırasında LA'nın zamana karşı değişiminin gözlenmesi, LA'nın kandan uzaklaştırılma hızının doğru olarak değerlendirilmesi için önem taşımaktadır. Böylece bu çalışmanın amacı, yüksek şiddetli egzersiz sonrasında $20 \mathrm{dk}$ süreli PT, kor egzersizleri ile kombine pasif toparlanmanın (PKT) ve AT'nin, LA'nın kandan uzaklaştırılma hızı üzerine etkisini araştırmaktır.

\section{YÖNTEM}

Araştırma Grubu: Bu çalışmaya takım veya güç/kuvvet sporlarında en az 4 yıl antrenman geçmişine sahip (4-12 yıl), 3-6 gün / hafta ve 5-13 saat / hafta antrenman yapan 11 (2 basketbol, 2 hentbol, 2 futbol, 1 Amerikan futbolu, 2 karate, 2 voleybol) erkek spor okulu öğrencisi (yaş $=25.7$ \pm 3.3 yıl, boy $=182.6 \pm 7.2 \mathrm{~cm}$, vücut yağ yüzdesi $=\% 12.25 \pm 3.2$ ) gönüllü olarak katılmıştır. Tüm katılımcılar kor egzersizleri ve Wingate testi (WanT) hakkında bilgi ve deneyime sahiptir. Ayrıca katılımcılara çalışma hakkında ayrıntıı ön bilgi verilmiş, kendilerinden, testlerden önceki günlerde yüksek şiddette antrenman yapmamaları istenmiştir. Katıımcılar en az iki gün ara ile üç kez laboratuvara davet edilmişler ve tüm testlere günün aynı saatlerinde (sabah veya öğleden sonra) ve son yemekten en az iki saat sonra girmişlerdir.
Antropometri: Katılımcıların boy uzunlukları ve vücut yağ yüzdeleri laboratuvara ilk gelişlerinde, vücut ağırlıkları her gelişlerinde ölçülmüştür. Boy $\pm 0.1 \mathrm{~cm}$ hassasiyette, duvara monte stadiometrede (Holtain Ltd., UK), vücut ağırlığı \pm 100 gr hassasiyetli baskülde (Seca, France) ölçülmüştür. Vücut yağ yüzdesi ve yağsız vücut kitlesi ayaktan ayağa biyoelektrik impedans analizöründe (Tanita TBF 350, USA) belirlenmiştir. Bunun için katılımcının boy uzunluğu cihaza kayıt edildikten sonra ölçüm tablası üzerindeki elektrotlara basmaları ve 10 sn hareketsiz kalması istenmiştir. Vücut kompozisyonu verileri cihazın yazıcısından çıktı olarak alınmıştır.

Egzersiz Testi: Katılımcılara her bir toparlanma öncesinde bilgisayar bağlantılı, kefeli Monark bisiklet ergometresinde (894E Pike Bike) standart Wingate testi yapılmıştır (Inbar ve diğ., 1996). Katılımcılar her bir testten önce $20 \mathrm{dk}$ oturur pozisyonda dinlendirildikten sonra telemetrik kalp atım monitörü (Polar 610i, Finlandiya) ile $5 \mathrm{dk} 5 \mathrm{sn}$ aralıklı olarak kalp atım hızları $\left(\mathrm{KAH}_{\text {din }}\right)$ ölçülmüştür. KAH kayıtları bilgisayara aktarılarak ortalaması hesaplanmıştır. $\mathrm{KAH}$ ölçümü esnasında kulak memesinden alınan kan örneklerinden dinlenik kan LA ( $\left.\mathrm{LA}_{\text {din }}\right)$ konsantrasyonları belirlenmiştir. Katılımcılar WanT'den önce 60-90 W aralığında 5 dk ısınmışlardır. Isınmanın 2. ve 4. dk'sında $10 \mathrm{sn}$ maksimal hızda pedal çevirmeleri istenmiştir. Üç dk pasif dinlenme sonrasında her katılımcı sele boyu ayarlandıktan ve ayakları klipslerle pedala bağlandıktan sonra vücut ağırlığının \% 7.5'ine karşılık gelen yükte 30 sn maksimal hızda pedal çevirmiştir. Her katılımcı test süresince sözel olarak motive edilmiştir. Zirve güç ( $Z G)$, ortalama güç $(O G)$ ve yorgunluk indeksi (YI) değerleri bilgisayardaki yazılım tarafından hesaplanmıştır. Test esnasında $\mathrm{KAH}$ telemetrik monitör ile 5 sn aralıklarla ölçülmüştür. En yüksek $\mathrm{KAH}$ değeri test sonu $\mathrm{KAH}\left(\mathrm{KAH}_{\mathrm{TS}}\right)$ olarak kayıt edilmiştir.

Toparlanma: Katılımcılara WanT sonrasında rastgele sıra ile PT, PKT ve AT protokolleri uygulanmıştır. 
Pasif Toparlanma: Katılımcılar PT esnasında WanT sonrasında $20 \mathrm{dk}$ sandalyede oturmuşlardır.

Aktif Toparlanma: AT bisiklet ergometresinde rezerv $\mathrm{KAH}^{\prime \prime \prime}$ \% 40'ına karşוlık gelen iş yükünde yapılmıştır. Rezerv KAH'ın \% 40'ı = $\mathrm{KAH}_{\text {din }}+\left[\left(\mathrm{KAH}_{\text {maks }}-\mathrm{KAH}_{\text {din }}\right) \times 0.40\right], \mathrm{KAH}_{\text {maks }}=$ 207 - $0.7 y a s ̧$ (Gellish ve diğ., 2007 ) formülünden hesaplanmıştır. Her katılımcı için Rezerv KAH'ın \% 40'ına karşılık gelen iş yükü; yük$\mathrm{KAH}$ ilişkisinden bireysel regresyon modellenerek hesaplanmıştır. Bunun için AT seansında WanT öncesinde bisiklet ergometresinde rezerv KAH'ın \% 40'ına karşılık gelen KAH'nı kapsayacak şekilde 3-4 kademeli bir submaksimal test yapılmıştır. Katıımcılar submaksimal test sonrasında KAH'ları dinlenik değere döndükten sonra WanT testine girmişlerdir. Submaksimal test 60 devir/dk pedal hızında $60 \mathrm{~W}$ başlangıç yükünde her $3 \mathrm{dk}$ 'da bir $30 \mathrm{~W}$ yük artışı şeklinde uygulanmıştır. Test esnasında KAH'ları telemetrik KAH monitörü (Polar 610i, Finlandiya) ile kayıt edilmiştir. KAH kayıtları bilgisayara aktarılmış ve yazılım programında her yükün son dk'sındaki ortalama KAH hesaplanarak kayıt edilmiştir. Bundan sonra Yük-KAH arasındaki ilişkiden excel programında bireysel doğrusal regresyon analizi yapıımıştır. $y=a+$ bx modelinden her katılımcının rezerv KAH'ın \% 40'ına karşılık gelen yük kestirilmiştir. y = Rezerv KAH'ın \% 40'ına karşılık gelen yük $a=$ regresyon sabiti, $b=$ regresyon katsayısı, $x=$ rezerv $K A H^{\prime} ı n$ \% 40'ına karşılık gelen $\mathrm{KAH}$. Tüm katılımcılar için regresyon denklemlerinde Yük-KAH ilişkisi için $R^{2}>0.990$ 'dır. Katılımcılar bisiklet ergometresinde bireysel regresyon modelinden hesaplanan iş yüklerinde 60 devir/dk pedal hızında 20 dk toparlanmışlardır.

Kor Egzersizleri ile Kombine Pasif ToparIanma: PKT seansında WanT sonrasında $5 \mathrm{dk}$ oturur pozisyonda pasif, $10 \mathrm{dk}$ stabil kor egzersizi ve $5 \mathrm{dk}$ oturur pozisyonda pasif olmak üzere 20 dk toparlanmışlardır. Kor egzersizleri 2 set ve 9 egzersiz [1. Tek kolda yan plank (Side plank with leg lift), 2. Süpermen hareketi (Superman's), 3. Kalca Köprüsü (Glute Bridge), 4. Beden desteği
(Plank), 5. Yan destek (Side plank), 6. Tek ayak ile kalça köprüsü (Single left glute bridge), 7 . El parmak uçlarında sabit şınav hareketi (Push up on fingertips static), 8. Sırt üstü posizyonunda topuk ve direkseklerden destek alarak kalçayı yukarı kaldırarak sabitleme (Lie on your back with your legs together and your arms under the scapula), 9. Kobra hareketi (Prone Cobro's)] ile sınırlandırılmıştır (Şekil 1). Her egzersiz 10 saniye eksentrik ve izometrik faz ve 10 saniye dinlenme şeklinde uygulanmıştır.

Laktik Asit Analizi: Kan LA konsantrasyonu $L A_{\text {din }}$, WanT'den hemen sonra $\left(L_{T S}\right)$, her bir toparlanma protokolünün 2., 5., 10., 15., ve 20. dk'larında kulak memesinden alınan 40-50 $\leftrightarrow \mathrm{L}$ kapiler kandan eletro enzimatik yöntemle ölçüm yapan analizörde (YSI Sport 1500, Yellow Spring Instrument, ABD) hemolize tam kan olarak ölçülmüştür.

Verilerin Analizi: Tüm değişkenlerin tanımlayıcı istatistikleri $(X \pm S D)$ yapıldıktan sonra, toparlanma protokollerinden önce ölçülen dinlenik değişkenler ( $K A H$ ve $L A$ ), Wingate testinde ölçülen güç değişkenleri ve testten hemen sonra ölçülen LA ve KAH arasındaki farklar için Tekrarlı Ölçümlerde Tek Yönlü Varyans Analizi, farklı toparlanma protokollerinin LA eliminasyonu üzerine etkisini belirlemek için $3 x$ 5 Tekrarlı Ölçümlerde Çift Yönlü Varyans Analizi (Toparlanma x Zaman) kullanılmıştır. KAH'daki değişimler için aktif toparlanma esnasında KAH sabit olduğu için (Şekil 3) PT ve PKT protokollerindeki KAH'ın zamana bağlı değişimleri arasındaki farklar 2 × 5 Tekrarlı Ölçümlerde Çift Yönlü Varyans Analizi (Toparlanma x Zaman) ile test edilmiştir. Toparlanma ProtokolIeri ve zamana bağlı değişimler için F istatistiği anlamlı çıktığında farkları belirlemek için Bonferroni Testi kullanılmıştır. Tekrarlı ölçümlerde küresellik varsayımı Mauchly's Testi ile kontrol edilmiştir. Küresellik varsayımı yerine gelmeyen değişkenlerde Epsilon $(\varepsilon),<0.75$ ise serbestlik derecesine Greenhouse-Geisser, > 0.75 ise Huynh-Feldt düzeltmesi uygulanmıştır (Winter ve ark., 2001). Deneme etki boyutu için (Effect Size), kısmi eta kare ( $\eta 2)$ hesaplanmıştır. Etki 


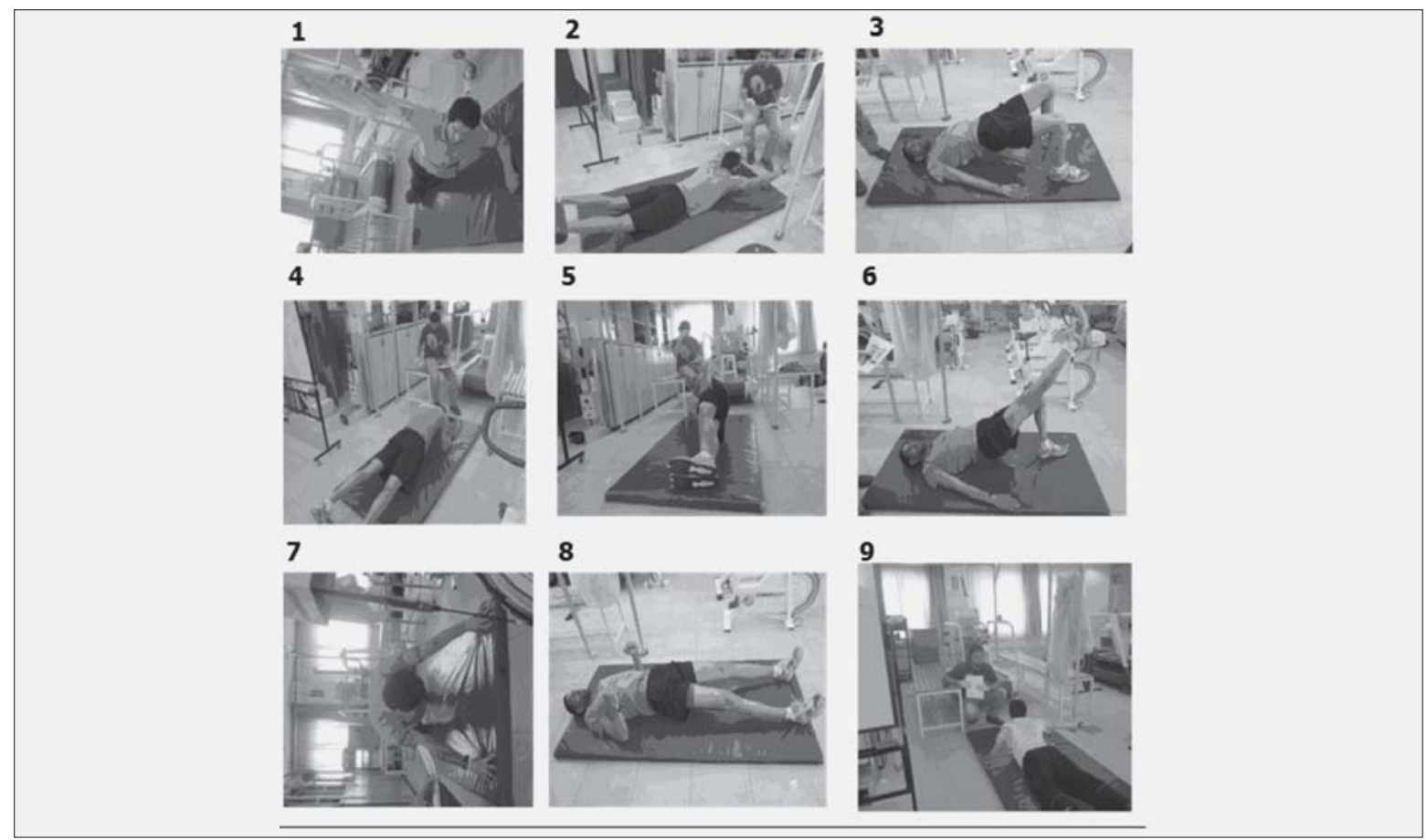

Şekil 1. Pasif toparlanma ile kombine uygulanan kor egzersizleri.

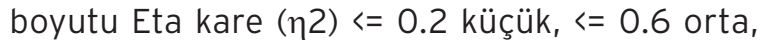
$<=1.2$ büyük, $<=2.0$ çok büyük, $<=4.0$ mükemmele yakın olarak sınıflandırılmıştır (Hopkins, 2002). Tüm istatistik analizler SPSS 15.0 paket programında yapılmış, $p=0.05$ yanılma düzeyi kullanılmıştır.

\section{BULGULAR}

Tablo 1'de gösterildiği gibi toparlanma protokolleri öncesinde ölçülen $V A, L_{\text {din }}$ ve $K A H_{\text {din }}$ benzer bulunmuştur ( $p>0.05$ ). Tablo 2'de toparlanma protokolleri öncesinde uygulanan WanT'deki güç çıktıları ve fizyolojik cevaplar gösterilmiştir. Toparlanma protokolleri öncesinde ölçülen güç ${ }_{\text {ort }}$ benzerdir (Tablo 2). PT protokolü öncesinde uygulanan WanT'de sergilenen güç zirve ve YI, PKT öncesine benzer, AT öncesinde ölçülenlerden anlamlı derecede yüksektir $(p<0.05)$. Bununla beraber her bir toparlanma öncesinde WanT'den hemen sonra ölçülen LA ve $\mathrm{KAH}$ değerleri benzerdir ( $p>0.05$ ) (Tablo 2 ).

Tablo 3'te farklı toparlanma protokolleri esnasında toparlanma zamanına bağlı olarak kan LA konsantrasyonlarındaki değişim verilmiştir. $3 \times 5$ (Toparlanma x zaman) tekrarlı ölçümlerde ANOVA sonuçları, farklı toparlanma protokolleri esnasında LA'nın kandan uzaklaştırılma hızları arasında anlamlı bir fark olmadığını göster-

Tablo 1. Toparlanma protokolleri öncesinde $V A, L A_{\text {din }}$ ve $K A H_{\text {din }}$ değerleri.

\begin{tabular}{ccccc}
\hline & $\begin{array}{c}\text { PT } \\
\text { Ort } \pm \text { Ss }\end{array}$ & $\begin{array}{c}\text { AT } \\
\text { Ort } \pm \text { Ss }\end{array}$ & $\begin{array}{c}\text { PKT } \\
\text { Ort } \pm \text { Ss }\end{array}$ & Kısmi $\eta^{2}$ \\
\hline VA(kg) & $80.8 \pm 6.5$ & $80.9 \pm 6.4$ & $81.1 \pm 7.0$ & 0.05 \\
\hline LADin & $1.35 \pm 0.33$ & $1.23 \pm 0.24$ & $1.19 \pm 0.30$ & 0.08 \\
\hline KAHDin & $81.4 \pm 15.7$ & $74.2 \pm 14.3$ & $83.4 \pm 10.5$ & 0.23 \\
\hline
\end{tabular}

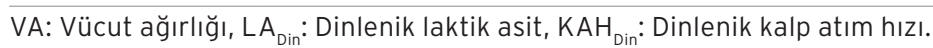


Tablo 2. Toparlanma protokollerinden önce uygulanan Wingate testinde ölçülen güç ve fizyolojik değişkenler.

\begin{tabular}{ccccc}
\hline & PT & AT & PKT & Kismi $\eta^{2}$ \\
\hline ZG (W/kg) & $10.75 \pm 1.40$ & $9.16 \pm 0.83$ & $9.78 \pm 1.33$ & 0.32 \\
\hline OG (W/kg) & $7.30 \pm 0.60$ & $7.45 \pm 0.83$ & $7.42 \pm 0.71$ & 0.05 \\
\hline YI (\%) & $51.7 \pm 7.7$ & $41.3 \pm 4.8$ & $45.4 \pm 8.1$ & 0.34 \\
\hline $\begin{array}{c}\text { LATS } \\
(\mathrm{mmol} / \mathrm{L})\end{array}$ & $7.18 \pm 1.44$ & $6.89 \pm 1.40$ & $6.67 \pm 2.07$ & 0.04 \\
\hline $\begin{array}{c}\text { KAHTS } \\
(\mathrm{a} / \mathrm{dk})\end{array}$ & $174.4 \pm 14.4$ & $180.5 \pm 20.0$ & $177.3 \pm 12.3$ & 0.08
\end{tabular}

ZG: Zirve güç, OG:Ortalama güç, YI:Yorgunluk indeksi, $\mathrm{LA}_{\mathrm{TS}}$ : Test sonu laktik asit, $\mathrm{KAH}_{\mathrm{TS}}$ : Test sonu kalp atım hızı.

Tablo 3. Toparlanma esnasında zamana bağlı olarak kan LA konsantrasyonlarındaki değişim.

\begin{tabular}{cccccc}
\hline & $\mathbf{2 . d k}$ & $\mathbf{5 . d k}$ & $\mathbf{1 0 . d k}$ & $\mathbf{1 5 . d k}$ & $\mathbf{2 0 . d k}$ \\
\hline PT & $11.81 \pm 2.53$ & $12.68 \pm 2.72$ & $12.23 \pm 2.84$ & $9.82 \pm 1.78$ & $8.17 \pm 1.98$ \\
\hline AT & $11.49 \pm 1.52$ & $12.65 \pm 2.47$ & $12.02 \pm 3.25$ & $9.41 \pm 2.96$ & $7.11 \pm 2.63$ \\
\hline PKT & $11.79 \pm 1.53$ & $12.86 \pm 1.52$ & $11.71 \pm 2.43$ & $9.51 \pm 2.99$ & $7.72 \pm 2.79$ \\
\hline
\end{tabular}

PT: Pasif toparlanma, AT: Aktif toparlanma, PKT: Kor egzersizleri ile kombine pasif toparlanma

miştir ( $p>0.05$, Kısmi $\eta^{2}=0.02$ ). Buna karşılık kan LA konsantrasyonları zamana bağlı olarak önemli derecede azalmıştır ( $p<0.05$, Kısmi $\eta^{2}$ = 0.83). 2., 5. ve 10. dk'da ölçülen kan LA konsantrasyonları arasındaki fark anlamlı değildir (p>0.05). 15. ve 20. dk'da ölçülen kan LA konsantrasyonları öncekilerden anlamlı derecede düşüktür (p<0.05). 20. dk'daki LA da 15. dk'daki LA'dan anlamlı derecede düşük bulunmuştur.
Bununla beraber kan LA konsantrasyonlarındaki azalma için Toparlanma Tipi x Zaman etkileşimi anlamlı değildir $\left(p>0.05\right.$, kısmi $\eta^{2}=$ 0.06) (Şekil 2).

Farklı toparlanma protokolleri esnasında $\mathrm{KAH}$ cevapları Şekil 3'te gösterilmiştir. Aktif toparlanma belirli bir iş yükünden gerçekleştiği için KAH cevapları zamana bağlı olarak sabit kalmıştır. PT ve PKT protokollerinde $\mathrm{KAH}$ ce-

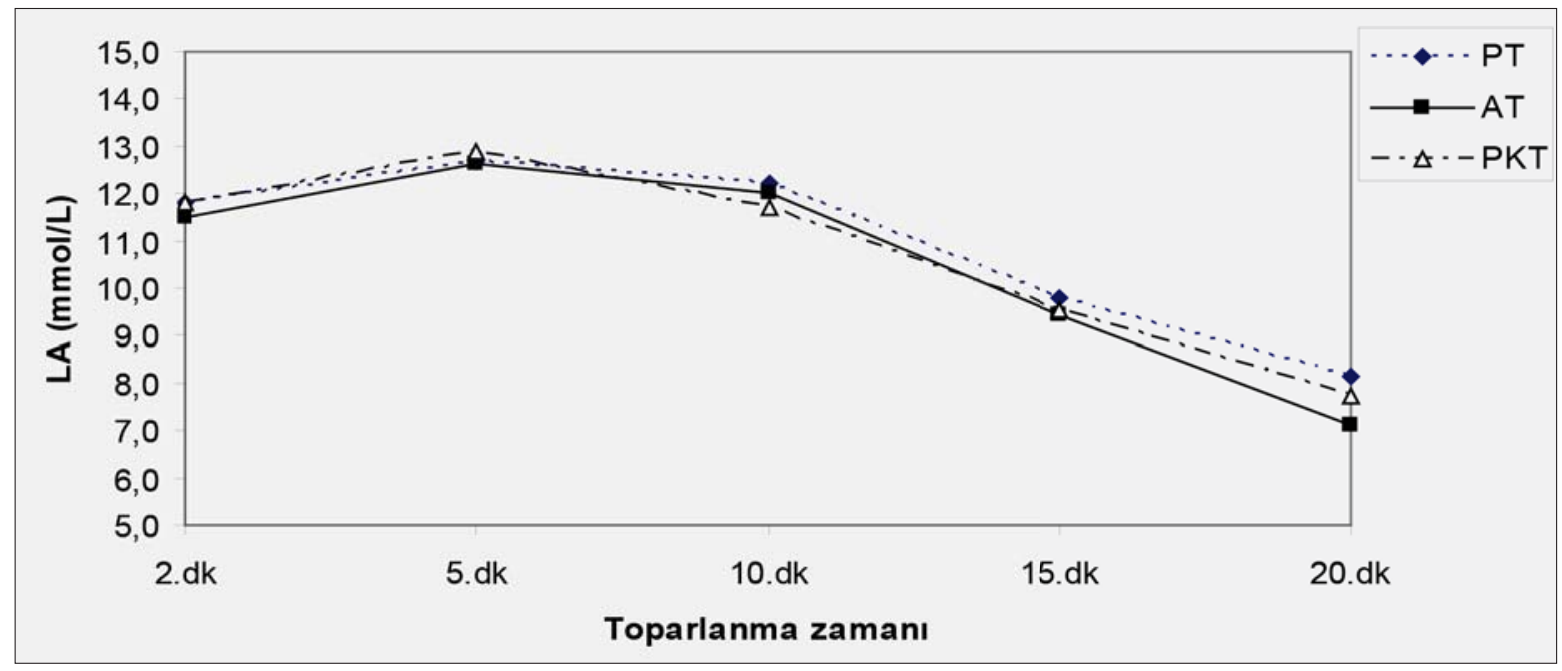

Şekil 2. Farklı toparlanma protokollerinde zamana bağlı olarak kan LA konsantrasyonlarındaki değişimler (Kısaltmalar Tablo 3'teki gibidir). 


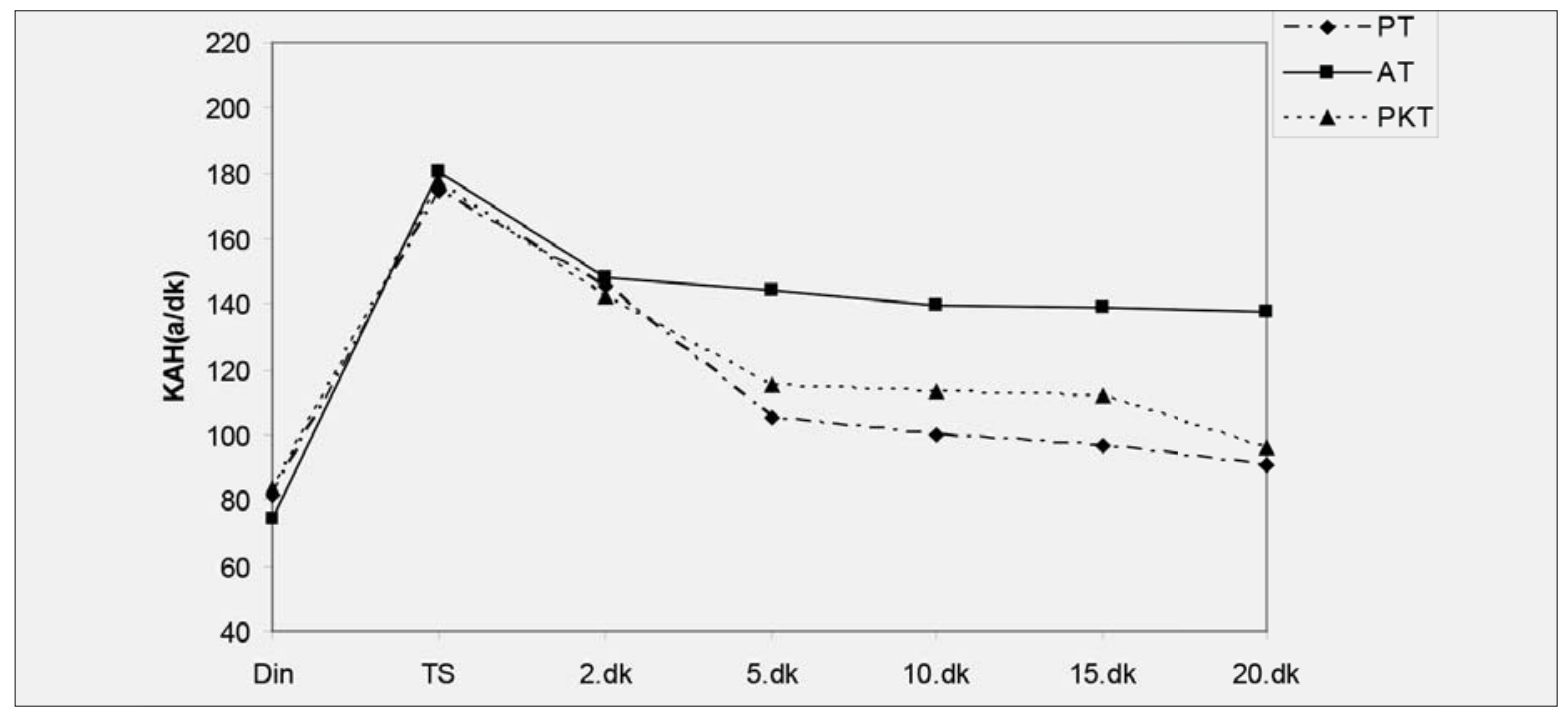

Şekil 3. Dinlenik (Din), test sonu (TS) ve toparlanma protokolleri esnasında zamana bağlı olarak KAH değişimi (Kısaltmalar tablo 3'te olduğu gibidir).

vapları arasında anlamlı fark saptanmamıştır ( $p>0.05$, kısmi $\eta^{2}=0.22$ ). Her iki toparlanma protokolünde KAH zamana bağlı olarak önemli derecede azalmıştır ( $p<0.05$, kısmi $\left.\eta^{2}=0.91\right)$. Toparlanmanın 2. dk'sındaki KAH sonrakilerden önemli derecede yüksek ( $p<0.05), 5 ., 10$. ve 15. dk'daki KAH'ları benzer ( $p>0.05$ ) ve her biri 20. dk'daki KAH'dan önemli derecede yüksektir $(p<0.05)$. KAH değişimi için Toparlanma Tipi $x$ Zaman etkileşiminin anlamlı olması ( $p<0.05$, kısmi $\eta^{2}=0.32$ ) zamana bağlı olarak KAH'daki azalmanın PT ve PKT protokolleri arasında önemli derecede farklı olduğunu göstermektedir.

\section{TARTIŞMA}

Yüksek şiddette tek seanslık anaerobik egzersiz sonrasında 20 dk'lık PT, KPT ve AT esnasında LA'nın kandan uzaklaştırılma hızlarının benzer olması bu çalışmanın ana bulgusudur. Toparlanma protokolleri öncesinde ölçülen $V A$, dinlenik $L A$ ve $K A H$ benzer bulunmuştur (Tablo 1). PT ve PKT öncesinde uygulanan WanT'da ölçülen ZG, OG ve YI benzer ( $p<0.05)$, AT öncesinde ölçülen $Z G$ ve $Y I, P T$ 'den düşüktür (Tablo 2). Bununla beraber WanT'den hemen sonra ölçülen $L_{T S}$ ve $\mathrm{KAH}_{\mathrm{TS}}$ benzer bulunduğu için PT'da ölçülen yüksek ZG ve YI fizyolojik cevaplara yansımamıştır. Dinlenik ve test sonrası fizyolojik cevaplar, deneklerin toparlanma protokollerinden önceki metabolik ve hormonal durumlarının ve test esnasındaki fizyolojik zorlanmalarının benzer düzeyde olduğunun bir göstergesi olarak kabul edilebilir.

Bu çalışmada egzersiz sonrasında kan LA konsantrasyonu toparlanmanın 10. dk'sından sonra PT, PKT ve AT protokollerinde zamana bağlı olarak önemli miktarda azalmıştır (Tablo 3 ). Buna karşılık Toparlanma Tipi x Zaman etkileşim istatistiği anlamlı değildir (Şekil 2). Bu bulgu, kandaki LA'nın zamana bağlı olarak azaldığını ve bu azalmanın tüm toparlanma protokollerinde benzer olduğunu gösterir. Bir başka deyişle tüm toparlanma protokollerinde zamana bağlı olarak LA'nın kandan uzaklaştırılma hızı benzerdir. AT esnasında kan LA konsantrasyonu toparlanma süreci boyunca PT ve PKT'dan düşük olmasına rağmen (Tablo 3) literatürdeki birçok çalışmanın sonuçlarının aksine istatistiksel olarak anlamlı bulunmamıştır. Tüm çalışmalarda olmamakla beraber (Toubekis ve diğ., 2011; Lau ve diğ., 2001), genel olarak AT esnasında LA'nın kandan uzaklaştırılma hızı PT'dan ve diğer toparlanma uygulamalarından önemli derecede yüksektir (Riganas ve diğ., 2015; Devlin ve diğ., 2014; Menzies ve diğ., 2010; Baldari ve diğ., 2005; Baldari ve diğ., 2004; Thiret ve diğ., 1993). Bu çalışmaların sonuçlarının aksine bazı çalışmalarda da AT ve PT'nin egzersiz sonrası 
LA kinetiği üzerine etkisi benzer bulunmuştur. Buz hokeycilerde yapılan bir çalışmada buzda paten testi sonrasında 15 dk süreli aktif ve pasif toparlanmada KAH ve LA cevaplarında ve sonraki egzersiz performansında anlamlı bir fark saptanmamıştır (Lau ve diğ., 2001). Bu çalışmada elde edilen bulgulara benzer şekilde yüzücülerde yapılan bir çalışmada pasif, $V_{2 \text { maks }}$ 'In \% 36'sı ve $V_{2 \text { maks }}$ 'In \% 59'una karşılık gelen şiddetlerde 6 dk süreli toparlanmada kan LA konsantrasyonlarında anlamlı bir değişim saptanmamıştır (Toubekis ve diğ., 2011). AT esnasında egzersizin şiddeti, LA'nın kandan uzaklaştırılma hızı üzerinde önemli bir faktördür (Bonen ve Belcastro 1976; Dodd ve diğ., 1984; Baldari ve diğ., 2004). LA aktif kaslarda mitokondride yakıt olarak kullanıldığı için egzersiz şiddeti (kasın metabolik aktivitesi ve enerji harcama hızı) ve kan akım hızı (Gladden, 2000) LA'nın kandan alınma hızını etkiler. Bununla beraber özellikle AT esnasında LA'nın optimal hızda eliminasyonunu sağlayan egzersiz şiddeti ile ilgili bir fikir birliği yoktur. $\mathrm{VO}_{2 \text { maks }}$ 'ın \% 40'ına karşılık gelen egzersiz şiddetinde Laktat/Pürivat oranı değişmediği ve indirgenmiş NAD konsantrasyonu azaldığı için bu egzersiz şiddetinde kasta tümüyle aerobik şartlar hakimdir (Sahlin ve diğ., 1987). Bu nedenle birçok çalışmada LA'nın kandan yüksek hızda eliminasyonu için aktif toparlanma esnasında optimal egzersiz şiddeti olarak $V_{2} O_{2 m a k s}$ 'In \% 40'ו (Belcastro ve Bonen, 1975; Gollnick ve diğ., 1986; Stamford ve diğ., 1981) ya da laktat eşiğine yakın veya laktat eşiğine karşılık gelen şiddetler (Baldari ve diğ., 2004) seçilmektedir. Ancak literatürde AT protokollerinde kullanılan egzersiz şiddetleri $\mathrm{VO}_{2 \text { maks }}$ 'In \% 30-80'i gibi çok geniş bir aralıkta değişmektedir. Bu çalışmada uygulanan rezerv KAH'ın \% 40'ına karşılık gelen egzersiz şiddeti literatürde AT'de kullanılan \% $\mathrm{VO}_{2 \text { maks }}$ şiddetleri aralığına karşılık gelmektedir. Rezerv KAH'ın yüzdelerine karşılık gelen egzersiz şiddetleri ile $\mathrm{VO}_{2 \text { maks }}$ 'In yüzdelerine karşıılık gelen egzersiz şiddetleri arasındaki ilişkiler popülasyon spesifik olup değişik gruplarda yapılan çalışmalarda rezerv KAH'ın \% 40'ına karşılık gelen egzersiz şiddetinin $\mathrm{VO}_{2 \text { maks }}$ 'ın \% 39'u ile 55'i arasında değiştiği (ortalama \% 43.4) (Da Cunha ve diğ., 2011) saptanmıştır. Birçok çalışmada laktat eşikte (Menzies ve diğ., 2010), bireysel anaerobik eşikte (\%39$60 \mathrm{VO}_{2 \text { maks }}$ ) (Baldari ve diğ., 2004) ve bireysel solunumsal eşikte (\% 50-67 $\mathrm{VO}_{2 \text { maks }}$ ) (Baldari ve diğ., 2005) ve bu eşiklerin altında ve üstünde yapılan farklı metabolik hızdaki aktif toparlanmalar esnasında LA'nın kandan uzaklaştırılma hızının pasif toparlanmadan daha yüksek ve birbirlerinden farklı olduğu saptanmıştır. Genel olarak bireysel anaerobik ve solunumsal eşik ve altındaki hızlarda yapılan AT'de LA'nın kandan uzaklaştırılma hızı, eşik üstü şiddette yapılan toparlanmadan daha yüksektir (Baldari ve diğ., 2005; Baldari ve diğ., 2004). Bununla beraber laktat eşiğinin altında çok düşük şiddette (laktat eşiğinin \% 40'ı) yapılan AT esnasında LA'nın kandan uzaklaştırılma hızının laktat eşiğinin altında ancak eşiğinin \% 80-100'üne karşılık gelen şiddette yapılan AT'den yavaş olduğu saptanmıştır (Menzies ve diğ., 2010). $\mathrm{Bu}$ çalışmada uygulanan rezerv KAH'ın \% 40'ına karşıllık gelen şiddetin, LA'nın kandan uzaklaştırılma hızında diğer toparlanma protokollerine (PT ve PKT) göre fark yaratmayacak kadar düşük kaldığı söylenebilir.

Bu çalışmada yüksek şiddette egzersiz sonrasında tüm vücut kaslarını aktifleştiren kor egzersizler esnasında kandan LA'nın uzaklaştırılma hızı PT ve AT'den farklı bulunmamıştır. Benzer şekilde PKT esnasında ölçülen KAH'da PT'de ölçülenden farklı değildir (Şekil 3). PKT'de ölçülen KAH'ın PT'den farklı olmaması kor egzersizlerin dolaşım sisteminde değişime neden olacak bir fizyolojik yük olarak yansımadığını göstermektedir. Yüksek şiddette egzersiz sonrasında LA'nın kandan uzaklaştırılması ile ilgili araştırma literatüründe kor egzersizlerin LA kinetiği üzerine etkisini inceleyen tek bir çalışmaya rastlanmıştır (Navalta ve Hrncir, 2007). Söz konusu çalışmada bu çalışmada olduğu gibi tek seanslık WanT sonrasında PT ve üç farklı kor egzersizi içeren toparlanmada LA'nın kandan uzaklaştırılma hızı üzerine etkisi toparlanmanın 
5. dk'sındaki tek bir ölçüm üzerinden incelenmiştir. Araştırmacılar 5. dk'daki kan LA konsantrasyonunun kor egzersizleri sonrasında PT'den anlamlı derecede düşük olduğunu göstermişlerdir (Navalta ve Hrncir, 2007). Bu bulgu bu çalışmada 2 set uygulanan 9 farklı egzersiz içeren kor egzersizi sonrasında elde edilen bulgularla çelişmekle beraber, Navalta ve Hrncir (2007)'nin çaIışmasında WanT'tan hemen sonra ölçülen ortalama kan LA konsantrasyonları (Kor eg.: 4.9, PT : $5.4 \mathrm{mmol} / \mathrm{L}$ ) bu çalışmada ölçülenlerden (PT: 7.18, PKT: 6.89) düşüktür. Ek olarak Navalta ve Hrncir (2007)'nin çalışmasında toparlanmanın 5. dk'da ölçülen kan LA konsantrasyonları kor egzersizli toparlanmada (5.9 mmol/L) PT'dan (7.6 mmol/L) düşük olmasına rağmen, WanT'tan hemen sonra ölçülenlerden yüksek olması her iki toparlanma esnasında henüz kas içi LA'nın tam olarak kana yansımadığı ve zirve konsantrasyona ulaşmadığının bir göstergesidir. Bu çalışmada toparlanmanın 2., 5., ve 10. dk'sında ölçülen LA konsantrasyonları arasında anlamlı fark saptanmamış olması kas içi LA'nın 5 dk'dan daha uzun bir süre sonra kanda zirve konsantrasyona ulaştığını göstermektedir. Bu nedenle yüksek şiddette egzersiz sonrasında değişik toparlanma protokollerinin kandan LA'nın uzaklaştırılması üzerine etkilerinin toparlanmanın 5. dk gibi erken dönemde tek bir ölçüm üzerinden değerlendirilmesi LA kinetiği hakkında yeterli olmayabilir. Nitekim Bonen ve Belcastro (1976) 1 mil koşusu sonrasında sürekli AT, kesintili AT ve PT esnasında 5.dk'da kan LA konsantrasyonları arasında anlamlı fark saptamamışlardır. Bunun yanında kor egzersizlerde aktifleşen kas grupIarının fibril tipi dağılımı da elde edilen bulgular arasındaki farkı açıklayabilir. Her ne kadar kor kasların (lumbar ve abdominal) fibril tipi dağılımı ile ilgili çalışmaların sonuçları, bu kaslar postürün korunmasında rol oynadıkları için başlıca oksidatif kapasiteleri yüksek Tip I ve Tiplla fibrillerden oluştuğunu göstermiş olmakla beraber, fibril tipi dağılımının kişiler arasında çok büyük değişkenlik gösterdiği de saptanmıştır (Thorstensson ve Carlson, 1987; Häggmark ve Thorstensson, 1979). Kandan LA'nın alınarak oksitlen- mesinde rol oynayan monokarboksil taşıyıcı 1 proteinleri Tip I ve Tiplla fibrillerde yüksek konsantrasyonda olduğu için oksidatif kapasitesi yüksek bu fibriller, LA'nın kandan uzaklaştırılma hızında önemli bir belirleyicidir (Juel, 2001). Bu nedenle bu çalışmadaki bireylerin kor kaslarının fibril kompozisyonu ile Navalta ve Hrncir (2007) çalışmasındaki bireylerin fibril kompozisyonu arasındaki farklar, bulgular üzerinde önemli bir faktör olabilir.

\section{SONUÇ ve ÖNERILER}

$\mathrm{Bu}$ araştırmanın bulguları, rezerv KAH'ın \% 40'ına karşılık gelen egzersiz şiddetinin AT esnasında LA'nın kandan uzaklaştırılma hızı üzerinde ölçülebilir bir fark yaratmadığını göstermiştir. Bunun yanında yüksek şiddette anaerobik egzersiz sonrasında spesifik olarak uygulanan kor egzersizleri de LA'nın kandan uzaklaştırılmasında PT ve AT'den farklı bir etki göstermemiştir. Bu sonuçlar anaerobik egzersizlerden sonra kandan LA'nın yüksek hızda uzaklaştırılması için AT'nin rezerv KAH'ın \% 40'ını aşan şiddetlerde uygulanması gerektiğini, kor egzersizlerin toparlanma sürecinde LA'nın kandan uzaklaştırılması amacıyla kullanılması için farklı egzersiz uygulamalarının denemesi ve daha fazla araştırma yapılması gerektiğini göstermektedir.

\section{Yazışma Adresi (Corresponding Address):}

Doç. Dr. Tahir Hazır

Hacettepe Üniversitesi, Spor Bilimleri Fakültesi, Egzersiz ve Spor Bilimleri Bölümü

E-posta: thazir@hacettepe.edu.tr

Telefon No: 03122976890

Faks No: 03122992167 


\section{K AY N A K L AR}

1. Adeva-Andany $M$, López-Ojén $M$, Funcasta-Calderón R, Ameneiros-Rodríguez E, Donapetry-García C, VilaAltesor M, Rodríguez-Seijas J. (2014). Comprehensive review on lactate metabolism in human health. $v, 17,76-$ 100.

2. Ali Rasooli S, Koushkie Jahromi M, Asadmanesh A, Salesi M. (2012). Influenc e of massage, active and passive recovery on swimming performance and blood lactate. J Sports Med Phys Fitness, 52(2), 122-7.

3. Allen DG, Lamb GD, Westerblad H. (2008). Skeletal muscle fatigue: Cellular mechanism. Physiol Rev, 88, 287-332.

4. Baldari C, Videira M, Madeira F, Sergio J, Guidetti L. (2005). Blood lactate removal during recovery at various intensities below the individual anaerobic threshold in triathletes. J Sports Med Phys Fitness, 45(4), 460-6.

5. Baldari C, Videira M, Madeira F, Sergio J, Guidetti L. (2004). Lactate removal during active recovery related to the individual anaerobic and ventilatory thresholds in soccer players. Eur J Appl Physiol, 93(1-2), 224-30.

6. Bangsbo J, Johansen L, Graham T, Saltin B. (1993). Lactate and $\mathrm{H}+$ effluxes from human skeletal muscles during intense, dynamic exercise. J Physiol, 462, 115-33.

7. Belcastro AN, Bonen, A. (1975). Lactic acid removal rates during controlled and uncontrolled recovery exercise. J Appl Physiol, 39, 932-936.

8. Bonen A, Belcastro AN. (1976). Comparison of selfselected recovery methods on lactic acid removal rates. Med Sci Sports, 8, 176-178.

9. Butcher SJ, Craven BR, Chilibeck PD, et al. (2007). The effect of trunk stability training on vertical takeoff velocity. J Orthop Sports Phys Ther. 37(5):223-231.

10. Brooks GA. (1991). Current concepts in lactate exchange. Med Sci Sports Exerc, 23, 895-906.

11. Da Cunha FA, Farinatti Pde T, Midgley AW. (2011). Methodological and practical application issues in exercise prescription using the heart rate reserve and oxygen uptake reserve methods. J Sci Med Sport, 14(1), 46-57.

12. Devlin J, Paton B, Poole L, Sun W, Ferguson C, Wilson J, Kemi OJ. (2014). Blood lactate clearance after maximal exercise depends on active recovery intensity. J Sports Med Phys Fitness, 54(3), 271-8.

13. Dodd S, Powers SK, Callender T, Brooks E. (1984). Blood lactate disappearance at various intensities of recovery exercise. J Appl Physiol, 57:1462-1465

14. Dupont G, Blondel N, Berthoin S. (2003). Performance for short intermittent runs: active recovery vs. passive recovery. Eur J Appl Physiol, 89(6), 548-54.

15. Dupont G, Moalla W, Guinhouya C, Ahmaidi S, Berthoin S. (2004). Passive versus active recovery during high-intensity intermittent exercises. Med Sci Sports Exerc, 36(2), 302-8.

16. Fukuba $Y$, Walsh ML, Morton RH, Cameron BJ, Kenny CTC, Banister EW. (1999). Effect of endurance training on blood lactate clearance after maximal exercise. Journal of Sports Sciences, 17(3), 239-248.

17. Gladden LB. (2000). Muscle as a consumer of lactate. Med Sci Sports Exerc, 32(4),764-71.
18 Gmada N, Bouhlel E, Mrizak I, Debabi H, Ben Jabrallah M, Tabka Z, Feki Y, Amri M. (2005). Effect of combined active recovery from supramaximal exercise on blood lactate disappearance in trained and untrained man. Int J Sports Med, 26(10), 874-9.

19. Gollnick PD, Bayly WM, Hodgson DR. (1986). Exercise intensity, training, diet, and lactate concentration in muscle and blood. Med Sci Sports Exer, 18, 334-340.

20. Greenwood JD, Moses GE, Bernardino FM, Gaesser GA, Weltman A. (2008). Intensity of exercise recovery, blood lactate disappearance, and subsequent swimming performance. J Sports Sci, 26(1), 29-34.

21. Gupta G, Goswami A, Sadhukhan AK, Mathar DN. (1996). Comparative study of lactate removal in short term massage of extremities, active recovery and a passive recovery period after supramaximal exercise sessions. Int J Sports Med, 17(2), 106-10.

22. Häggmark T, Thorstensson A. (1979). Fibre types in human abdominal muscles. Acta Physiol Scand, 107(4), 319-25.

23. Hemmings B, Smith M, Graydon J, Dyson R. (2000). Effects of massage on physiological restoration, perceived recovery, and repeated sports performance. Br J Sports Med, 34(2), 109-14.

24. Heyman E, De Geus B, Mertens I, Meeusen R. (2009). Effects of four recovery methods on repeated maximal rock climbing performance. Med. Sci. Sports Exerc, 41(6), 1303-1310.

25. Hides JA, Jull GA, Richardson CA. (2001). Longterm effects of specific stabilization exercises for firstepisode low back pain. Spine. 26(11), E243-248.

26. Hopkins WG. (2002). A scale of magnitudes for effect statistics: A new view of statistics Available from URL :http:// sportsci.org/resource/stats/effectmag.html

27. Imai A, Kaneoka K, Okubo Y, Shiraki H. (2014). Effects of two types of trunk exercises on balance and athletic performance in youth soccer players. The International Journal of Sports Physical Therapy, 9(1), 47-57.

28. Inbar, O., Bar-Or, O. \& Skinner, S.J. (1996). The Wingate Anaerobic Test. Champain: Human Kinetics Books.

29. Juel C. (2001). Current aspects of lactate exchange: lactate/ $\mathrm{H}+$ transport in human skeletal muscle. Eur $\mathrm{J}$ Appl Physiol, 86(1), 12-6.

30. Kahle NL, Gribble PA. (2009). Core stability training in dynamic balance testing among young, healthy adults. Athletic Training and Sports Health Care, 1(2), 65-73.

31. Lopes FA, Panissa VL, Julio UF, Menegon EM, Franchini E. (2014). The effect of active recovery on power performance during the bench press exercise. $J$ Hum Kinet, 9(40), 161-9.

32. Martin NA, Zoeller RF, Robertson RJ, Lephart SM. (1998). The comparative effects of sports massage, active recovery, and rest in promoting blood lactate clearance after supramaximal leg exercise. J Athl Train, 33(1), 30-5.

33. Masi FD, De Souza Vale RG, Dantas EH, Barreto AC, Novaes Jda S, Reis VM. (2007). Is blood lactate removal during water immersed cycling faster than during cycling on land? J Sports Sci Med, 6(2), 188-92. 
34. McAinch AJ, Febbraio MA, Parkin JM, Zhao $\mathrm{S}$ Tangalakis K, Stojanovska L. Carey MF. (2004). Effect of active versus passive recovery on metabolism and performance. Int J Sport Nutr Exerc Metab, 14(2), 185-96.

35. Medbo JI, Jebens E, Noddeland H, Hanem S, Toska K. (2006). Lactate elimination and glycogen resynthesis after intense bicycling. Scand J Clin Lab Invest, 66(3) 211-26.

36. Menzies $\mathbf{P}$, Menzies $C$, Mclntyre L, Paterson P, Wilson J, Kemi OJ. (2010). Blood lactate clearance during active recovery after an intense running bout depends on the intensity of the active recovery. J Sports Sci, 28(9), 975-82.

37. Miladi I, Temfemo A, Mandengue SH, Ahmaidi S. (2011). Effect of recovery mode on exercise time to exhaustion, cardiorespiratory responses, and blood lactate after prior, intermittent supramaximal exercise. J Strength Cond Res, 25(1), 205-210.

38. Monedero J, Donne B. (2000). Effect of recovery interventions on lactate removal and subsequent performance. Int J Sports Med, 21, 593-597.

39. Navalta JW, Hrncir SP. (2007). Core stabilization exercises enhance lactate clearance following highintensity exercise. J Strength Cond Res, 21(4), 1305-9.

40. Ouergui I, Hammouda O, Chtourou H, Gmada N Franchini E. (2014). Effects of recovery type after a kickboxing match on blood lactate and performance in anaerobic tests. Asian J Sports Med, 5(2), 99-107.

41. Palmer TN, Fournier PA. (1997). Replenishment of muscle glycogen after high-intensity exercise: a role for intramuscular lactate glyconeogenesis? Biochem Soc Trans, 25, 25-30.

42. Paoli A, Bianco A, Battaglia G, Bellafiore M, Grainer A Marcolin G, Cardoso CC, Dall'aglio R, Palma A. (2013). Sports massage with ozonised oil or non-ozonised oil: Comparative effects on recovery parameters after maximal effort in cyclists. Phys Ther Sport, 14(4), 240-5.

43. Prieske O, Muehlbauer $T$, Borde R, Gube M, Bruhn $S_{\text {, }}$ Behm DG, Granacher U. (2016). Neuromuscular and athletic performance following core strength training in elite youth soccer: Role of instability. Scand J Med Sci Sports, 26(1), 48-56.

44. Riganas CS, Papadopoulou Z, Psichas N, Skoufas D, Gissis I, Sampanis M, Paschalis V, Vrabas IS. (2015) The rate of lactate removal after maximal exercise: the effect of intensity during active recovery. J Sports Med Phys Fitness, 29. [Epub ahead of print] PubMed PMID: 25920410.

45. Robertson A, Watt JM, Galloway SD. (2004). Effects of leg massage on recovery from high intensity cycling exercise. Br J Sports Med, 38(2), 173-6.

46. Robergs RA, Ghiasvand F, Parker D. (2004) Biochemistry of exercise-induced metabolic acidosis. Am J Physiol Regul Integr Comp Physiol, 287(3), R502-16.

47. Sahlin K., Katz A., Henriksson J. (1987). Redox state and lactate accumulation in human skeletal muscle during dynamic exercise. Biochem J, 245, 551-556.

48. Sharma A, Geovinson SG, Singh Sandhu J. (2012) Effects of a nine-week core strengthening exercise program on vertical jump performances and static balance in volleyball players with trunk instability. $J$ Sports Med Phys Fitness, 52(6), 606-615.
49. Sato K, Mokha M. (2009). Does core strength training infl uence running kinetics, lower-extremity stability, and 5000-M performance in runners? J Strength Cond Res, 23(1), 133-140.

50. Scanlan AT, Madueno MC. (2016). Passive recovery promotes superior performance and reduced physiological stress across different phases of shortdistance repeated sprints. J Strength Cond Res, DOI: 10.1519/JSC.0000000000001339

51. Shirey $M$, Hurlbutt $M$, Johansen $N$, King GW Wilkinson SG, Hoover DL. (2012). The influence of core musculature engagement on hip and knee kinematics in women during a single leg squat. Int J Sports Phys Ther, $7(1), 1-12$.

52. Spencer M., Bishop D, Dawson B, Goodman C, Duffield R. (2006). Metabolism and Performance in Repeated Cycle Sprints: Active versus Passive Recovery. Med. Sci. Sports Exerc, 38(8), 1492-1499.

53. Spencer M, Dawson B, Goodman C, Dascombe B, Bishop D. (2008). Performance and metabolism in repeated sprint exercise: effect of recovery intensity. Eur J Appl Physiol, 103, 545-552.

54. Stamford BA, Weltman A, Moffatt R, Sady S. (1981). Exercise recovery above and below anaerobic threshold following maximal work. J Appl Physiol, 51, 840-844.

55. Taoutaou Z, Granier P, Mercier B, Mercier J, Ahmaidi S, Prefaut C. (1996). Lactate kinetics during passive and partially active recovery in endurance and sprint athletes. Eur J Appl Physiol O, 73(5), 465-470

56. Thiriet P, Gozal D, Wouassi D, Oumarou T, Gelas H, Lacour JR. (1993). The effect of various recovery modalities on subsequent performance in consecutive supramaximal exercise. J Sports Med Phys Fit, 33, 118-129.

57. Thorstensson A, Carlson H. (1987). Fibre types in human lumbar back muscles. Acta Physiol Scand, 131(2), 195-202.

58. Toubekis AG, Adam GV, Douda HT, Antoniou PD, Douroundos II, Tokmakidis SP. (2011). Repeated sprint swimming performance after low- or high-intensity active and passive recoveries. J Strength Cond Res, 25(1),109-16.

59. Toubekis AG, Tsolaki A, Smilios I, Douda HT, Kourtesis T, Tokmakidis SP. (2008). Swimming performance after passive and active recovery of various durations. Int J Sports Physiol Perform, 3(3), 375-86.

60. van Hall G. (2010). Lactate kinetics in human tissues at rest and during exercise. Acta Physiol (Oxf), 199(4), 499-508.

61. van Hall G. (2000). Lactate as a fuel for mitochondrial respiration. Acta Physiol Scand. 168(4), 643-56.

62. Willardson JM. (1997). Core stability training: Applications to sports conditioning programs. $J$ Strength Cond. Res, 21(3), 979-985.

63. Winter EM, Eston RG, Lamb KL. (2001). Statistical analyses in the physiology of exercise and kinanthropometry. Journal of Sports Sciences, 19:10, 761-775.

64.Zhang Y, Tang S, Chen G, Liu Y. (2015). Chinese massage combined with core stability exercises for nonspecific low back pain: a randomized controlled trial. Complement Ther Med, 23(1), 1-6. 